\title{
ON THE HARDY PROPERTY OF MIXED MEANS
}

\author{
PAWEŁ PASTECZKA
}

Abstract. Hardy property of means has been extensively studied by Páles and Pasteczka since 2016. The core of this research is based on few of their properties: concavity, symmetry, monotonicity, repetition invariance and homogeneity (last axiom was recently omitted using some homogenizations techniques). In the present paper we deliver a study of possible omitting monotonicity and replacing repetition invariance by a weaker axiom.

These results are then used to establish the Hardy constant for certain types of mixed means.

Mathematics subject classification (2020): 26E60, 26D15.

Keywords and phrases: Hardy inequality, Hardy constant, convexity, subinvariance, power means, mixed means.

\section{REFERENCES}

[1] F. Bernstein And G. Doetsch, Zur Theorie der konvexen Funktionen, Math. Ann., 76 (4): 514526, 1915.

[2] T. CARleman, Sur les fonctions quasi-analitiques, Conférences faites au cinquième congrès des mathématiciens scandinaves, Helsinki, page 181-196, 1932.

[3] B. C. Carlson, R. K. Meany, And S. A. Nelson, Mixed arithmetic and geometric means, Pacific J. Math., 38 (2): 343-349, 1971.

[4] J. Chudziak, Zs. PÁles, And P. PAsteczKa, From the Ingham-Jessen property to mixed-mean inequalities, J. Math. Anal. Appl., 2021, doi:10.1016/j.jmaa.2021.124999.

[5] J. Duncan And C. M. McGregor, Carleman's inequality, Amer. Math. Monthly, 110 (5): 424431, 2003.

[6] G. H. HARDY, Note on a theorem of Hilbert, Math. Zeitschrift, 6: 314-317, 1920.

[7] G. H. Hardy, J. E. Littlewood, And G. Pólya, Inequalities, Cambridge University Press, Cambridge, 1934 (first edition), 1952 (second edition).

[8] T. Kaluza AND G. Szego, Über Reihen mit lauter positiven Gliedern, J. London Math. Soc., 2: 266-272, 1927.

[9] K. S. Kedlaya, Proof of a mixed arithmetic-mean, geometric-mean inequality, Amer. Math. Monthly, 101 (4): 355-357, 1994.

[10] K. Knopp, Über Reihen mit positiven Gliedern, J. London Math. Soc., 3: 205-211, 1928.

[11] A. N. Kolmogorov, Sur la notion de la moyenne, Rend. Accad. dei Lincei (6), 12: 388-391, 1930.

[12] A. Kufner, L. Maligranda, And L. E. Persson, The Hardy Inequality: About Its History and Some Related Results, Vydavatelský servis, 2007.

[13] E. LANDAU, A note on a theorem concerning series of positive terms, J. London Math. Soc., 1: 38-39, 1921.

[14] P. PasteczKa, On some Hardy type inequalities involving generalized means, Publ. Math. Debrecen, 87 (1-2): 167-173, 2015.

[15] J. E. PeČAriĆ And K. B. Stolarsky, Carleman's inequality: history and new generalizations, Aequationes Math., 61 (1-2): 49-62, 2001.

[16] Zs. PÁles And P. PastecZKa, Characterization of the Hardy property of means and the best Hardy constants, Math. Inequal. Appl., 19 (4): 1141-1158, 2016.

[17] Zs. PÁles ANd P. PAsteczKa, On the homogenization of means, Acta Math. Hungar., 159 (2): 537-562, 2019. 
[18] Zs. PÁles AND P. PASteCZKa, On Hardy type inequalities for weighted quasideviation means, Math. Inequal. Appl., 23 (3): 971-990, 2020.

[19] Zs. PÁles AND L.-E. Persson, Hardy type inequalities for means, Bull. Austr. Math. Soc., 70 (3): 521-528, 2004.

[20] R. KH. SAdikova, Comparison of discrete mixed means that contain symmetric functions, Mat. Zametki, 80 (2): 262-269, 2006.

[21] Y.-D. WU, ZH.-H. ZHANG, AND ZH.-G. WANG, The best constant for Carleman's inequality of finite type, Acta Math. Acad. Paedagog. Nyházi. (N. S.), 24 (2): 235-241, 2008. 